\title{
APP ADOPTION AND SWITCHING BEHAVIOR: APPLYING THE EXTENDED TAM IN SMARTPHONE APP USAGE
}

\section{Subhadin Roy}

Indian Institute of Management, Udaipur, India

\begin{abstract}
The increasing use of mobile applications have been escalating with the increasing use of smartphones. In the present study, we examine (a) the adoption behavior of mobile apps using the extended TAM framework, and (b) whether adoption leads to subsequent use behavior and switching intentions. Based on data collected from two surveys in India we test the conceptual model of extended TAM and the effects of behavior on switching intentions using factor analysis and structural equation modeling. The major findings indicate a significant effect of most predictor variables on the perceived usefulness and perceived ease of use of apps. Further, we found a significant effect of behavioral intention on use behavior and subsequent switching intentions to apps from computers/laptops.
\end{abstract}

Keywords: Mobile Applications (APPS); App Adoption; Switching Behavior; Extended TAM; Structural Equation Modeling 


\section{INTRODUCTION}

Escalating advances in information and communication technology has led to huge awareness for the mobile phones having extra features, generally known as smartphones (Hassan et al. 2014). Advances in technology has enabled mobile devices to have advanced computing ability and data connectivity through wireless services, such as Wi-Fi and 4G, which has led to the advent of the smartphones (Middleton, 2010). The increase in the smartphone consumers have resulted in the growth and rising use of mobile applications (apps) to meet the various needs of the consumer for any plausible purpose. Mobile applications (apps) are defined as "small programs that run on a mobile device and perform tasks ranging from banking to gaming and web browsing" (Taylor et al. 2011, p. 60). Mobile apps "cut through the clutter of domain name servers and uncalibrated information sources, taking the user straight to the content he or she already values" (Johnson, 2010, p. 24) as the consumer does not require to connect through an internet browser. Technically, mobile apps allow the users to perform specific tasks that can be installed and run on a range of portable digital devices such as smartphones and tablets (Liu, Au \& Choi 2014). Mobile apps (which can be commercial or non-commercial) offer a wide range of services. For example, apps could be related to stock markets, sports, shopping, maps, banking, news, travel etc. In addition to informative usefulness, there are many apps that satisfy entertainment usefulness, such as game apps, social media (Facebook), and music. According to Accenture (2012), consumers assume that there should be an app for everything. In other words, everything should be "appified" (Hassan, et al. 2014). Apps provide customized and focused information services with the location awareness function. Apps are more user friendly, can be less expensive and easier to download and install compared to desktop applications (Taylor, Voelker, and Pentina 2011). Apps can satisfy both hedonic and utilitarian values depending on the app type and the usage need (Wang, Liao \& Yang 2013).

Since both smartphones and apps are used with high levels of engagement, marketers have started to promote their brands via apps (Gupta 2013). During the last few years, mobile applications have become a fully-fledged market. Globally, users spend on an average, $82 \%$ of their mobile minutes with apps and just 18\% with web browsers (Gupta 2013).Marketers are utilizing the mobile apps for engage consumers in two-way interactions that enhance consumer loyalty and overall brand engagement (Chiem et al. 2010). Apps are considered as a novel channel of brand communication (Hutton \& Rodnick 2009). Easy availability of apps represents a significant reason for consumers to make the switch from traditional PC and mobile phones to smartphones.

However, researchers have not yet focused on the entire process of consumer use of mobile apps (and subsequent switching from devices such as computers and laptops). Even though researchers have investigated the effect of App usability on use behavior (Hoehle \& Venkatesh 2015) or app availability and market performance (Lee \& Raghu 2014), they have not considered the antecedents of adoption nor the switching behavior. There is a need to understand the antecedents of App usage and its effect on subsequent use behavior. For a marketer, the understanding of whether customers would switch from a pc or a laptop to apps is important since it would have multiple ramifications for strategy formulation (Gupta 2013). This becomes even more important since business over the world is shifting to digital modes 
of communication and transaction (Bhattacharjee et al. 2011). From a theoretical perspective, a complete model of consumer adoption of apps (including antecedents theoretical) and its consequences would benefit the academia in marketing and IS research. This becomes important from the contextual value of testing of an IS theory in a different setting (in this case mobile apps) (Hong et al. 2014) that is important both for research and for solving problems at the managerial/practical level (Lee \& Baskerville 2003).

Thus, the objective of the present study is to examine the adoption of mobile apps using the technology acceptance model framework (namely TAM3 of Venkatesh and Bala, 2008) and the subsequent effects of the main TAM constructs on behavioral and switching intentions. The rest of the paper is organized as follows: in the next section, we provide a brief literature review of TAM and its relevance in mobile app adoption leading to the research objectives. Subsequently, we discuss the research methodology and the major results. We follow this up with the discussions and the managerial implications before concluding the paper.

\section{LITERATURE REVIEW}

\subsection{Technology Acceptance Model}

A review of mobile marketing literature (Okazaki \& Barwise 2011) showed Technology Acceptance Model (TAM) to be the most widely applied theory in recent studies. In this regard, Technology Acceptance Model (TAM) is a well-accepted theory for explaining the user's intention to adopt technological innovations (Davis 1993).The adoption of technological products and services is explained by TAM and its extensions: TAM2 (Venkatesh \& Davis 2000) and TAM 3 (Venkatesh \& Bala 2008). The modifications to the original TAM have been necessitated by the constant development of new and more sophisticated IT devices (Nysveen et al. 2005). TAM suggests that perceived usefulness (PU) and perceived ease of use (PEU) are beliefs about a new technology that influence an individual's attitude toward and use of that technology (Davis et al. 1989). These beliefs influence the usage intentions, drive adoption and subsequent usage behavior. PU is defined as "the degree to which an individual believes that using a particular system would enhance his or her job performance" and PEU is defined as, "the degree to which an individual believes that using a particular system would be free of physical and mental effort" (Davis 1993). TAM researchers suggest that the adoption of mobile devices is influenced by both the perceived usefulness and ease of use, and the behavior and attitudes of the consumers' social network (Lu, Yao \& Yu 2005). TAM has been useful to various technologies (e.g. word processors, email, WWW, Management Information Systems) in various situations (e.g., time and culture) with different control factors (e.g., gender, organizational type and size) and different subjects (e.g. undergraduate students, MBAs, and knowledge workers), leading its proponents to believe in its strength (Lee, Kozar \& Larsen 2003).

Venkatesh and Davis (2000) revised the TAM model into TAM2 because of the influence of social forces. TAM2 examines the antecedents of perceived usefulness and incorporates subjective norms (such as social influence) and cognitive instruments (job relevance, image, quality, and result demonstrability) on adoption (Venkatesh \& Davis 2000). TAM2 was developed to support certain components of TAM (such as the effect of subjective norms) whose effects on technology adoption were unclear. TAM2 thus posits three social influence mechanisms - compliance, internalization, and identification to affect the social 
influence processes (Venkatesh \& Bala, 2008). Compliance represents a situation in which an individual performs certain behavior in order to attain certain rewards or avoid punishment (Miniard \& Cohen, 1979). Identification refers to an individual's belief that performing a behavior will elevate his or her social status within a referent group because important referents believe the behavior should be performed (Venkatesh \& Davis, 2000). Internalization is defined as the incorporation of a referent's belief into one's own belief structure (Warshaw, 1980). TAM2 hypothesizes that subjective norm and cognitive instruments influence perceived usefulness and behavioral intention that would further satisfy the users as they gain more experience with the technology. Venkatesh et al. (2003) synthesized these models into the unified theory of acceptance and use of technology (UTAUT). UTAUT integrated four key factors (i.e., performance expectancy, effort expectancy, social influence, and facilitating conditions) and four moderating variables (i.e., age, gender, experience, and voluntariness). All the eight factors were proposed to predict behavioral intentions to use a technology (and actual used) primarily in organizational context (Venkatesh, Davis \& Morris 2007).

Subsequently, TAM3 was proposed as an advancement of TAM2 to enable the understanding of the role of interventions in technology adoption. TAM3 presents a complete nomological network of the determinants of individuals' IT adoption and use (Venkatesh \& Bala 2008). TAM3 posits that the effect of perceived ease of use on behavioral intention will diminish and the effect of perceived ease of use on perceived usefulness will increase with increasing experience with a technology (Venkatesh \& Bala 2008).

\subsection{TAM and Mobile Commerce}

As an extension of e-commerce, mobile commerce (m-commerce) is considered a separate channel that can deliver value by offering convenience and accessibility anywhere, anytime (Balasubramanian et al. 2002; Koet al. 2009). The additional value created by mobile services for consumers is derived from being accessible independent of time and place (Balasubramanian et al. 2002; Chen \& Nath 2004), and being customized based on time, location and personal profile (Figge 2004). Mobile devices provide advanced mobile services, including banking, commerce, shopping, games, information, thereby facilitating mobile commerce. The adoption of technological products and services (in connection with mcommerce) has been predominantly explained using TAM and its extensions. TAM has been used to predict the attitudes and behavior of users of mobile services, based on perceived usefulness (PU) and perceived ease of use (PEU) of mobile systems (Nicolas, Castillo \& Bouwman 2008). For mobile services, researchers suggest that the consumers' peers and the social network influence the adoption and use of both the device and the technology (Taylor, Voelker \& Pentina 2011; Nicolas, Castillo \& Bouwman 2008; Lu, Yao \& Yu 2005). Therefore, further study of this relationship is required to determine the usefulness of TAM in customer adoption of mobile apps.

\subsection{Mobile Commerce and Apps}

A key driver of the success of mobile marketing is the acceptance and use by consumers since the power of m-marketing depends on the extent of consumer responsiveness (Heinonen \& Strandvik 2007). Hence, investigating consumers' switching intentions from PC's towards mobile apps has assumed new importance. Apart from being convenient, apps have huge potential for mobile commerce (m-commerce). Mobile commerce refers to any transactions, 
either direct or indirect, with a monetary value implemented via a wireless telecommunication network (Barnes 2002). Apps offer variety of services that facilitate m-commerce as they can be used anytime and anywhere. Mobile apps enable consumers to take care of daily tasks as a consumer can use an app to make purchases, pay bill/ online transactions, locate stores, financial transactions, get driving directions/cabs, browse menus and reviews of local (and notso-local) restaurants, thus facilitating M-commerce. The adoption rates of mobile apps are becoming increasingly critical in the business realm due to ease-of-use, quick access to specialized content and engaging functionality (Jones, 2014).In addition to representing an opportunity for advertising and branding, apps hold potential as a mobile commerce channel (Taylor, Voelker \& Pentina 2011). It empowers shoppers with the ability to gather information on the spot from multiple sources, check on product availability, special offers and alter their selection at any point along the path to purchase (Lai, Debbarma \& Ulhas 2012). Thus, the consumer shopping modality is quickly and decisively changing from traditional shopping and PC-based online shopping to mobile shopping (Ali et al. 2011; Butcher 2011) through various apps. Obviously, the rate of adoption of mobile devices as shopping platforms is impressive, outpacing the initial rate of adoption for personal computers as a shopping channel (Ali et al. 2011). Apps save time and effort of consumers as they can do the work anytime and from anywhere (apps reduces the need to be physically present at a place) without the hassle of logging to laptops/computers. Hence, marketers are embracing mobile apps as a platform for communication and consumer interaction as they are more cost efficient than traditional ads and may sometimes create entirely new revenue stream (Gupta 2013).

\subsection{TAM and Mobile Apps}

The obvious question that both the academic and the practitioners would be asking is, what drives a consumer to adopt an app? This becomes more important when the app is a commercial app unlike social media or free music apps as the stakes would be higher. This is where technology adoption (that includes personal and social factors) becomes important. Researchers suggest that the adoption of mobile devices is influenced by both the perceived usefulness and ease of use, and the behavior and attitudes of the consumers' social network (Lu, Yao, \& Yu 2005). For example, Shi (2009) investigated the factors influencing users' intentions to adopt app and revealed that some factors such as enjoyment and facilitating conditions are significantly influencing users' attitude and intention to use apps. In addition, $\mathrm{Wu}$, Kang \& Yang (2015) found perceived usefulness, self-efficacy, and peer influence to be the key determinants of users' attitude toward and intention to purchase paid apps. In the context of mobile devices, social influence is important, as the adoption of these devices is often used to enhance the consumer's sense of self-importance and social status (Sarker and Wells 2003).

\section{JUSTIFICATION AND STUDY OBJECTIVE}

Despite mobile application adoption being an emerging concept in mobile marketing, our literature review revealed that there is a lack of theoretical and methodological clarity on holistically evaluating mobile application adoption. Though smartphone apps represent an important part of mobile marketing strategies, little research has examined the consumers' evaluations and uses of apps from a user-centric perspective. Even though, Hoehle \& Venkatesh (2015) developed a scale to measures app usability, it did not explore the adoption 
behavior of apps (which could be a very important factor of investigation, specifically for developing nations).

Earlier researchers (e.g. Rousseau \& Fried 2001; Johns 2001) have considered context to be a sensitizing device that makes an individual more aware of the potential situational and temporal boundary conditions to theories. However, later researchers have opined that context is a critical driver of cognition, attitudes and behavior, or a moderator of relationships among such lower-level phenomena (Bamberger 2008; Whetten 2009). Thus, the generalizability of any theory in different settings is important both for research and for managing and solving practical problems in organizations (Lee \& Baskerville 2003). Such "situation linking" makes the models more accurate and the interpretation of results more robust (Bamberger 2008). For example, in a study of information and communication technology implementation, Venkatesh et al. (2010) replicated the job characteristics model (JCM; Hackman \& Oldham 1980) that was developed based on theory and data from western contexts, in the new context of a service organization in a developing country, i.e., a bank in India. Similarly we have replicated the TAM 3 model in mobile apps context under the settings of developing country i.e., India. An understanding of adoption behavior would also enable the marketer to understand the consumer better and devise strategies accordingly. Thus, there is both a theoretical and a managerial need for an in-depth study of the way adoption of apps is prevalent in young consumers.

The present study aims to investigate the adoption of commercial apps and its subsequent effect of use and switching behavior. The study draws from the fundamental constructs of TAM 3 (Venkatesh \& Bala 2008) and introduces the same (with modifications) in the context of commercial mobile app adoption. The present study goes beyond TAM3 by including a switching behavior construct as a consequence of commercial app adoption. Thus, the present study has two objectives. First, it aims to explore the influence of the major technology adoption constructs (i.e. TAM3) on commercial app adoption. Second, it investigates the effect of adoption and use behavior on subsequent switching behavior. The model that summarizes the conceptual model tested in the study is given in figure 1 .

\section{RESEARCH METHODOLOGY}

\subsection{Measures}

The measures for the TAM3 constructs were derived from Venkatesh and Bala (2008). In the present study, switching behavior implies the shift of consumers from using traditional channels of commerce such as stores and electronic commerce through computers to app based commerce. Because of unavailability of a direct instrument measuring switching behavior, a set of items were generated based on two focus group discussions (FGD). The discussions were conducted among 16 ( 8 in each groups) participants with means age 27 (gender balanced). The FGDs also generated information about the overall use of apps and the types of apps used by the participants. The FGD findings also indicated banking, travel booking and fashion shopping to be the most frequently used shopping apps by the consumers. The FGD findings generated 12 items related to switching behavior. Subsequently, the items were discussed with an expert panel and five items were retained for the main study. The final questionnaire had 55 items (measuring 15 constructs) measured on seven point Likert scales (1=Strongly Disagree; $7=$ Strongly Agree) with additional questions on demographics and smartphone usage. 


\subsection{Data Collection}

The main study was conducted over two months in 2015 in two phases. Young and young adults were selected as the target population, since this is the major target segment for smartphones (Hampton et al. 2011; Walsh, et al. 2011). A large Indian university was selected to conduct the study that had graduate and executive program students. In study 1 , three hundred students in the MBA program were invited to participate in the survey. This was to test for dimensionality and validity of the study constructs. In this phase, use behavior and switching intentions was not included (total scale items in questionnaire $=47$ ). Before beginning the survey, the participants were shown an educative video on smartphone apps with specific focus on a fashion-shopping app. After the video was shown, they were asked to complete the questionnaire thinking about apps in general but with focus to the specific app shown for Perceived Usefulness, Perceived Ease of Use and Behavioral Intention. The total number of usable responses in phase 1 was 268 (average age 24, male female ratio close to 60:40). 


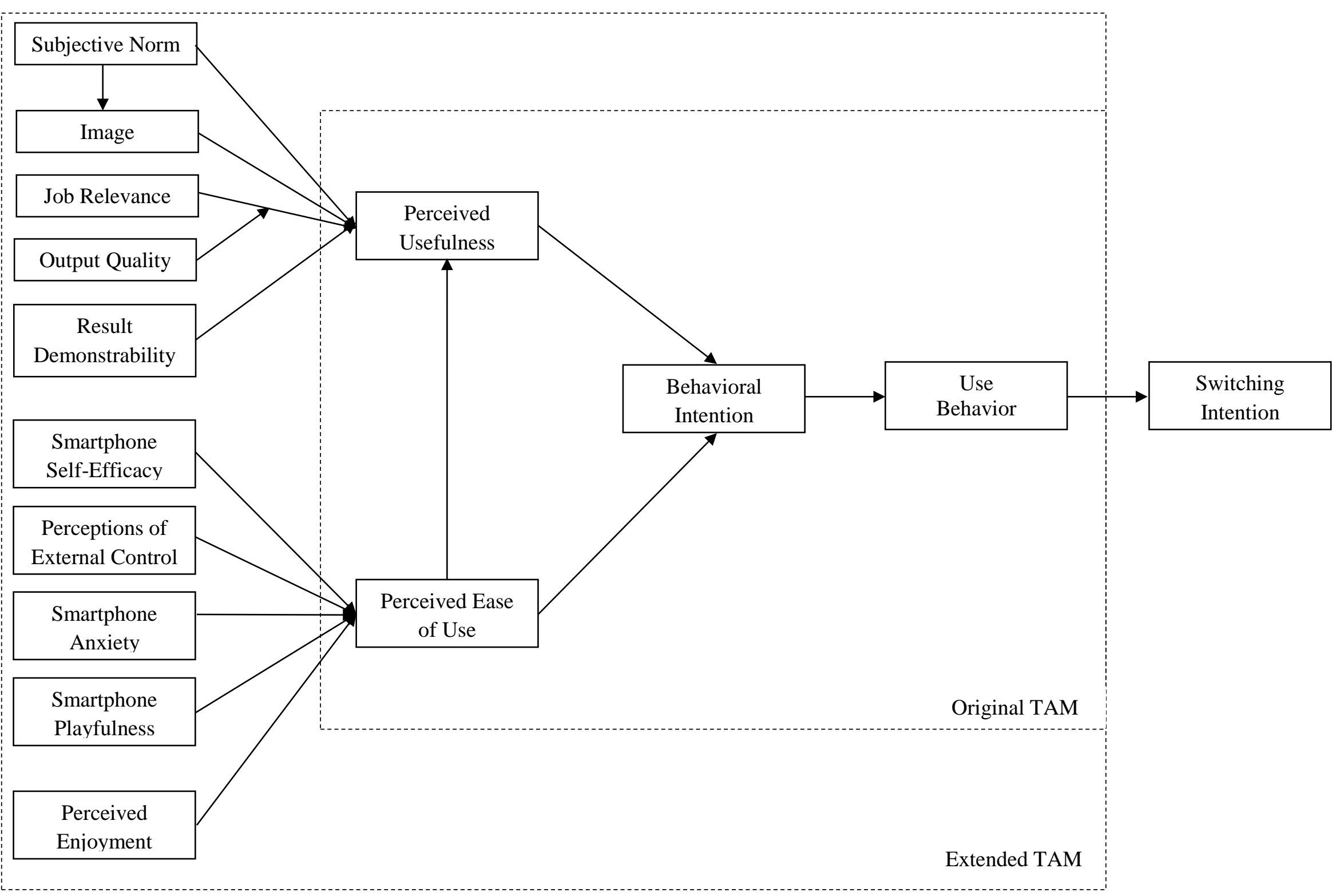

Figure 1. The Conceptual Model 
In study 2, a new sample of 300 students were selected in phase 2 and randomly divided into three groups. The screening criterion used was that the participant should not have a commercial app already installed in his/her smartphone. Each group was then asked to install either a) a banking app; b) a travel booking app; and c) fashion shopping app (names of apps given to the participants a priori). The participants were instructed to use the app for a fortnight (as per their convenience). The survey was conducted on the $15^{\text {th }}$ day. The questionnaire included use behavior and switching intention questions (along with TAM3 questions) in this phase (total scale items in questionnaire $=55$ ). Thus, all 15 study constructs were measured in study 2 . In study 2 , the usable questions received were 281 (average age 27, male female ratio around 55:45).

\section{RESULTS}

\section{Study 1: Exploratory Factor Analysis, Confirmatory factor Analysis and Construct Validation}

Researchers recommend exploratory factor analysis (EFA) as a precursor to confirmatory analysis of measurement items since it provides an initial overview of the latent variables and helps in identifying redundant items (Netemeyer, Bearden, \& Sharma 2003; Lewis, Templeton, \& Byrd 2005). Thereby, EFA helps to measure 'purification' (Churchill, 1979), and allows a researcher to delete, add or modify measurement items based on the results (Smith, Milberg, \& Burke, 1996). Even though we selected established measures of adoption and use behavior, we first conducted an exploratory factor analysis (EFA) to ensure that the dimensional structure of the study constructs were similar to those found in erstwhile literature. This was done to ensure that the nature of the constructs (as measured by the items) was perceived in the same way in India that they are in western countries. Researchers have hinted that measures developed in a specific cultural context may not hold true for a different culture and thus applying scales developed in a specific culture may suffer from an etic or pseudo etic trap while being used in another context (Craig \& Douglas, 2000; Ford, West and Sargeant 2015).

To this end, we used principal components analysis with Varimax rotation. The 47 items resulted in a 13-factor solution with the 44items loadings above 0.55 (Table 1). Based on poor loadings, we removed three items to obtain a better factor structure without distorting the nature of the constructs (Hair et al. 2008). The Eigen values the factors ranged from 1.11 to 3.2 after rotation. The internal consistency reliability (measured through Cronbach's Alpha) of all the 13 factors were above 0.6 for the 49 items solution (Kline 2011). 
Table 1. Study 1: EFA Table

\begin{tabular}{|c|c|c|c|c|c|c|c|}
\hline Construct/items & Mean (s.d.) & $\begin{array}{c}\text { Factor } \\
\text { Loading }\end{array}$ & $\begin{array}{c}\text { Coefficient } \\
\text { Alpha }\end{array}$ & Construct/items & Mean (s.d.) & $\begin{array}{c}\text { Factor } \\
\text { Loading }\end{array}$ & $\begin{array}{c}\text { Coefficient } \\
\text { Alpha }\end{array}$ \\
\hline Subjective Norm (SN1) & $3.91(1.18)$ & .707 & \multirow{4}{*}{0.68} & $\begin{array}{c}\text { Smartphone } \\
\text { Playfulness (SPL1) }\end{array}$ & $5.11(1.09)$ & .692 & \multirow{3}{*}{0.72} \\
\hline SN2 & $4.27(1.14)$ & .790 & & SPL2 & $5.50(1.16)$ & .820 & \\
\hline SN3 & $4.38(1.59)$ & .750 & & SPL3 & $5.46(1.66)$ & .695 & \\
\hline SN4 & $4.97(1.08)$ & .614 & & $\begin{array}{c}\text { Perceived } \\
\text { Enjoyment (ENJ1) }\end{array}$ & $5.73(1.28)$ & .853 & \multirow{3}{*}{0.77} \\
\hline Image (IMG1) & $3.71(1.03)$ & .798 & \multirow{3}{*}{0.76} & ENJ2 & $5.50(1.02)$ & .887 & \\
\hline IMG2 & $3.48(1.07)$ & .855 & & ENJ3 & $6.84(0.46)$ & .821 & \\
\hline IMG3 & $3.83(1.11)$ & .813 & & $\begin{array}{c}\text { Perceived } \\
\text { Usefulness (PU1) }\end{array}$ & $4.98(1.06)$ & .825 & \multirow{4}{*}{0.76} \\
\hline Job Relevance (REL1) & $5.21(1.32)$ & .811 & \multirow{3}{*}{0.68} & PU2 & $4.39(1.15)$ & .728 & \\
\hline REL2 & $4.98(1.03)$ & .762 & & PU3 & $4.94(1.12)$ & .823 & \\
\hline REL3 & $4.90(1.17)$ & .761 & & PU4 & $5.54(1.47)$ & .662 & \\
\hline Output Quality OUT1 & $5.18(1.04)$ & .792 & \multirow{3}{*}{0.74} & $\begin{array}{l}\text { Perceived Ease of } \\
\text { Use (PEU1) }\end{array}$ & $5.68(1.30)$ & .583 & \multirow{4}{*}{0.71} \\
\hline OUT2 & $4.81(1.06)$ & .822 & & PEU2 & $4.66(1.09)$ & .675 & \\
\hline OUT3 & $5.00(1.16)$ & .862 & & PEU3 & $5.68(1.45)$ & .877 & \\
\hline $\begin{array}{c}\text { Result Demonstrability } \\
\text { (RES1) }\end{array}$ & $5.57(1.26)$ & .789 & \multirow{3}{*}{0.71} & PEU4 & $5.21(1.54)$ & .802 & \\
\hline RES2 & $5.79(1.02)$ & .796 & & $\begin{array}{c}\text { Behavioral } \\
\text { Intention (BI1) }\end{array}$ & $4.76(1.06)$ & .849 & \multirow{3}{*}{0.73} \\
\hline RES3 & $5.63(1.18)$ & .751 & & $\mathrm{BI} 2$ & $4.66(1.22)$ & .827 & \\
\hline $\begin{array}{c}\text { Smartphone self-efficacy } \\
\text { (SSE1) }\end{array}$ & $5.03(1.04)$ & .861 & \multirow{4}{*}{0.74} & $\mathrm{BI} 3$ & $4.19(1.19)$ & .819 & \\
\hline SSE2 & $4.61(1.40)$ & .876 & & & & & \\
\hline SSE3 & $3.76(1.19)$ & .852 & & & & & \\
\hline SSE4 & $4.90(1.03)$ & .874 & & & & & \\
\hline $\begin{array}{c}\text { Perceptions of External } \\
\text { Control (PEC1) }\end{array}$ & $5.29(1.26)$ & .711 & \multirow[t]{2}{*}{0.64} & & & & \\
\hline PEC2 & $4.14(1.04)$ & .828 & & & & & \\
\hline
\end{tabular}

JISTEM USP, Brazil Vol. 14, No. 2, May/Aug., 2017 pp. 239-261 www.jistem.fea.usp.br $\quad$ (cc) EY 


\begin{tabular}{ccc}
\hline PEC3 & $5.39(1.17)$ & .711 \\
\hline $\begin{array}{c}\text { Smartphone Anxiety } \\
\text { (SNX1) }\end{array}$ & $2.89(2.02)$ & .614 \\
\hline SNX2 & $2.65(1.13)$ & .794 \\
\hline SNX3 & $2.62(1.09)$ & .855 \\
\hline SNX4 & $2.46(1.08)$ & .856 \\
\hline
\end{tabular}


EFA does not allow detailed tests for convergent and discriminant validity of sub-constructs of a scale (Hair et al., 2008). Thus, we further analyzed the data using confirmatory factor analysis (CFA) using maximum likelihood as the method of estimation using Amos 20. Scale development papers (Churchill, 1979) suggest a fresh dataset for conducting CFA. However, we used the same data for two reasons: a) we used scales that were already validated and found to have face validity for the Indian audience; and b) our study objective was exploration and not measure development.

Each sub-dimension (the thirteen first order factors) was first tested using independent measurement models that yielded satisfactory fit statistics. Subsequently, we ran a complete measurement model with all first order constructs (FOC) correlated to each other. The model displayed good fit (Chi square/df= 2.5; GFI=0.94; $\mathrm{AGFI}=0.91 ; \mathrm{NFI}=0.94 ; \mathrm{CFI}=0.93 ; \mathrm{RMR}=0.06$; RMSEA $=0.07$ ) calibrations did not reveal any high modification index (above 6) and thus, all 44 items were retained in the solution. The standardized factor loadings for the items displayed statistically significant $t$ values (Table 2). The Average Variance Extracted (AVE) for all FOCs was above 0.6 as per standard cut-offs suggested by researchers (Hair et al., 2008) and all factors displayed adequate construct reliability through composite reliability (CR)/Joreskog's Rho coefficients above 0.7 as per guidelines proposed by Chin (1998) (Table 2). Thus, the convergent validity of the thirteen FOCs of our conceptual model was established.

To test for discriminant validity, the squared inter-factor correlations between each factor were compared with the AVE values of each construct (as per the approach suggested by Fornell \& Larcker 1981). The diagonal values of the AVE's were larger than the non-diagonal values of the squared inter construct correlations and thus discriminant validity was achieved.

Table 2. Study 1: CFA Results and Construct Reliability Measures

\begin{tabular}{|c|c|c|c|}
\hline Construct/Items & \begin{tabular}{c|c|} 
Std. \\
Loading
\end{tabular} & t Value & $\mathbf{p}$ \\
\hline \multicolumn{4}{|l|}{ Subjective Norm $(\mathrm{CR}=0.90, \mathrm{AVE}=0.67, \alpha=0.66)$} \\
\hline People who influence my behavior think that I should use APPs & 0.85 & 4.23 & $<.001$ \\
\hline People who are important to me think that I should use APPs & 0.82 & 4.46 & $<.001$ \\
\hline My peers/tech experts have been helpful in my learning of the use of APPs & 0.79 & 4.70 & $<.001$ \\
\hline In general, my social/ college environment has supported the use of APPs & 0.81 & & \\
\hline \multicolumn{4}{|l|}{ Image $(\mathrm{CR}=0.86, \mathrm{AVE}=0.67, \alpha=0.71)$} \\
\hline $\begin{array}{l}\text { People in my college/social circle who use APPs have more prestige than } \\
\text { those who do not }\end{array}$ & 0.69 & 5.75 & $<.001$ \\
\hline
\end{tabular}




\begin{tabular}{|c|c|c|c|}
\hline People in my college/social circle who use APPs have a high profile & 0.89 & 5.36 & $<.001$ \\
\hline Having the latest APPs is a status symbol in my college/social circle & 0.86 & & \\
\hline \multicolumn{4}{|l|}{ Task Relevance $(\mathrm{CR}=0.89, \mathrm{AVE}=0.71, \alpha=0.73)$} \\
\hline In my daily activities, usage of APPs is important & 0.91 & 5.99 & $<.001$ \\
\hline In my daily activities, usage of APPs is relevant & 0.89 & 7.12 & $<.001$ \\
\hline The use of APPs is pertinent to my various daily activities & 0.73 & & \\
\hline \multicolumn{4}{|l|}{ Output Quality $(\mathrm{CR}=0.84, \mathrm{AVE}=0.66, \alpha=0.77)$} \\
\hline The quality of the output/help I get from APPs is high & 0.85 & 7.87 & $<.001$ \\
\hline I have no problem with the quality of the APP's output & 0.82 & 6.83 & $<.001$ \\
\hline I rate the results from the APPs to be excellent & 0.75 & & \\
\hline \multicolumn{4}{|c|}{ Result Demonstrability $(\mathrm{CR}=0.86, \mathrm{AVE}=0.67, \alpha=0.74)$} \\
\hline I have no difficulty telling others about the results of using the APPs & 0.83 & 4.13 & $<.001$ \\
\hline I believe I could communicate to others the benefits of using the APPs & 0.86 & 4.17 & $<.001$ \\
\hline The results of using the APPs are clear to me & 0.76 & & \\
\hline \multicolumn{4}{|c|}{$\begin{array}{c}\text { Smartphone self-efficacy }(\mathrm{CR}=0.94, \mathrm{AVE}=0.80, \alpha=0.73)(\mathrm{I} \text { am able to complete a job/activity using an } \\
\text { APP } \ldots\end{array}$} \\
\hline ... even if there was no one around to tell me what to do & 0.91 & 5.35 & $<.001$ \\
\hline ... even if I had just the built-in help facility for assistance. & 0.88 & 4.44 & $<.001$ \\
\hline ... only if someone showed me how to do it first & 0.92 & 3.33 & $<.01$ \\
\hline $\begin{array}{l}\text {...only if I had used similar App/software before this one to do the same } \\
\text { job/activity. }\end{array}$ & 0.87 & & \\
\hline Perceptions of External Control $(\mathrm{CR}=0.89, \mathrm{AVE}=\mathrm{C}$ & $\alpha=0$. & & \\
\hline
\end{tabular}




\begin{tabular}{|c|c|c|c|}
\hline I have control over using the APP & 0.83 & 3.06 & $<.01$ \\
\hline I have the resources necessary to use the APP & 0.87 & 3.32 & $<.01$ \\
\hline $\begin{array}{l}\text { Given the resources, opportunities and knowledge it takes to use the APP, } \\
\text { it would be easy for me to use the APP }\end{array}$ & 0.83 & & \\
\hline \multicolumn{4}{|l|}{ Smartphone Anxiety $(\mathrm{CR}=0.89, \mathrm{AVE}=0.67, \alpha=0.71)$} \\
\hline Smartphone Apps do not scare me at all & 0.73 & 2.77 & $<.01$ \\
\hline Working with a Smartphone App makes me nervous & 0.82 & 4.16 & $<.001$ \\
\hline Smartphone Apps make me feel uncomfortable & 0.85 & 4.09 & $<.001$ \\
\hline Smartphone Apps make me feel uneasy & 0.86 & & \\
\hline \multicolumn{4}{|c|}{$\begin{array}{c}\text { Smartphone Playfulness }(\mathrm{CR}=0.84, \mathrm{AVE}=0.64, \alpha=0.72)(\text { how you would characterize yourself when } \\
\text { you use an App) }\end{array}$} \\
\hline ... spontaneous & 0.76 & 4.75 & $<.001$ \\
\hline ... creative & 0.84 & 6.51 & $<.001$ \\
\hline ...p playful & 0.81 & & \\
\hline \multicolumn{4}{|c|}{ Perceived Enjoyment $(\mathrm{CR}=0.92, \mathrm{AVE}=0.80, \alpha=0.82)$} \\
\hline I find using APPs to be enjoyable. & 0.89 & 7.42 & $<.001$ \\
\hline The actual process of using APP is pleasant. & 0.92 & 7.08 & $<.001$ \\
\hline I have fun using APPs. & 0.88 & & \\
\hline \multicolumn{4}{|l|}{ Perceived Usefulness $(\mathrm{CR}=0.88, \mathrm{AVE}=0.63, \alpha=0.79)$} \\
\hline Using the APP improves my performance in my daily activities. & 0.86 & 3.91 & $<.01$ \\
\hline Using the APP increases my productivity. & 0.75 & 7.50 & $<.001$ \\
\hline Using the APP enhances my effectiveness in my daily activities. & 0.85 & 6.54 & $<.001$ \\
\hline I find the APP to be useful in my daily activities. & 0.73 & & \\
\hline
\end{tabular}


Perceived Ease of Use $(\mathrm{CR}=0.91, \mathrm{AVE}=0.72, \alpha=0.73)$

\begin{tabular}{|l|c|c|c|}
\hline My interaction with the APP is clear and understandable. & 0.76 & 3.62 & $<.01$ \\
\hline Interacting with the APP does not require a lot of my mental effort. & 0.83 & 5.19 & $<.001$ \\
\hline I find the APP to be easy to use. & 0.97 & 6.93 & $<.001$ \\
\hline I find it easy to get the APP to do what I want it to do. & 0.82 & & \\
\hline
\end{tabular}

Behavioral Intention $(\mathrm{CR}=0.90, \mathrm{AVE}=0.74, \alpha=0.69)$

\begin{tabular}{|l|c|c|c|}
\hline Assuming I had access to the APP, I intend to use it. & 0.89 & 4.45 & $<.001$ \\
\hline Given that I had access to the APP, I predict that I would use it. & 0.84 & 6.00 & $<.001$ \\
\hline I plan to use the APP till it becomes out-dated. & 0.86 & & \\
\hline \multicolumn{1}{|c|}{ Use Behaviour (CR=0.86, AVE=0.69, $\alpha=0.81)$} & 5.64 & $<.001$ \\
\hline $\begin{array}{l}\text { I am likely to use smartphone APPs for various commercial activities in } \\
\text { the near future. }\end{array}$ & 0.79 & 5.53 & $<.001$ \\
\hline $\begin{array}{l}\text { I am likely to use smartphone APPs to shop for products and services in } \\
\text { the near future. }\end{array}$ & 0.83 & 5.53 \\
\hline $\begin{array}{l}\text { I am likely to use smartphone APPs for entertainment services in the near } \\
\text { future. }\end{array}$ & 0.85 & & \\
\hline \multicolumn{1}{|c|}{ Switching Intention (CR=0.89, AVE=0.73, $\alpha=0.80)$} & \\
\hline $\begin{array}{l}\text { It is likely that I would use smartphone APPs instead of a computer/laptop } \\
\text { for my commercial needs in the near future. }\end{array}$ & 0.89 & 2.78 & $<.01$ \\
\hline $\begin{array}{l}\text { It is likely that I would use smartphone APPs instead of a computer/laptop } \\
\text { for my product/service needs in the near future. } \\
\text { for my entertainment needs in near future }\end{array}$ & 0.82 & 3.21 & $<.01$ \\
\hline
\end{tabular}

Note: Values for Use Behaviour and Switching Intention relate to study 2. 


\section{Study 2: Validation of the Conceptual Model}

In study 2, the conceptual model (Figure 1) containing the antecedents of app adoption and its consequences was estimated using structural equation modelling. Thus, the questions in study 2 included items on behavioral intention and switching behavior. We first conducted EFA for the use behavior and switching constructs (with factor loadings above 0.7 for a two factor solution with three items each for use behavior and switching intention). Before running the complete model, we first conducted tests for the complete measurement models for the 15 study constructs. The measurement model yielded a good fit (Chi square/df $=1.8 ; \mathrm{GFI}=0.92$; $\mathrm{AGFI}=0.89$; NFI=0.92; $\mathrm{CFI}=$ $0.91 ; \mathrm{RMR}=0.05$; RMSEA $=0.06$ ) and the standardized loadings of the first 13 constructs were found significant and similar to the values in study 1 . The two new constructs in study 2 were also found to have significant standardized loading and high AVE values (Table 2, last eight rows). We conducted a discriminant validity test for the study 2 constructs similar to that in study 1 and the AVE values for all study constructs were found to be higher than their respective squared correlations (Table 3).

Hence, we conducted the path analysis for the complete model. In the present study, we created an interaction term for task relevance (REL) X output quality (OUT) using summated product terms of the items in the respective constructs. In this regard, we used the process suggested by Hayes (2015) and Hayes and Agler (2014) modified for structural equation modelling. The estimation method used was maximum likelihood in AMOS 20. The model fit was reasonably good (Chi square/df=4.4; GFI=0.95; $\mathrm{AGFI}=0.92 ; \mathrm{NFI}=0.92 ; \mathrm{CFI}=0.93 ; \mathrm{RMR}=0.04 ; \mathrm{RMSEA}=0.06$ ) (Table 4).The multiple $\mathrm{R}$ square values for all endogenous variables were significant (Table 4). Subjective norms, result demonstrability and perceived ease of use were found to have a significant effect on perceived usefulness. The Job Relevance-Output quality interaction term was found to have a significant effect on perceived usefulness in such a way that with growing output quality, the effect of job relevance on perceived usefulness gets better. All variables modelled to affect perceived ease of use (i.e. Smartphone Self Efficacy; Perceptions of External Control; Smartphone Anxiety; Smartphone Playfulness and Perceived Enjoyment)were found to have a significant effect. Both perceived usefulness and perceived ease of use were found to have significant effects on behavioral intention (with perceived usefulness having a higher affect). Behavioral intention was found to affect use behavior and use behavior was found to affect switching intention. 
Table 3. Study 2: Discriminant Validity Test Results

\begin{tabular}{|c|c|c|c|c|c|c|c|c|c|c|c|c|c|c|c|}
\hline & $\mathbf{S N}$ & IMG & REL & OUT & RES & SSE & PEC & SNX & SPL & ENJ & PEU & PUI & BI & USE & SWT \\
\hline SN & 0.67 & & & & & & & & & & & & & & \\
\hline IMG & 0.26 & 0.67 & & & & & & & & & & & & & \\
\hline REL & 0.11 & 0.13 & 0.71 & & & & & & & & & & & & \\
\hline OUT & 0.06 & 0.14 & 0.25 & 0.66 & & & & & & & & & & & \\
\hline RES & 0.17 & 0.08 & 0.24 & 0.27 & 0.67 & & & & & & & & & & \\
\hline SSE & 0.12 & 0.07 & 0.04 & 0.12 & 0.08 & 0.80 & & & & & & & & & \\
\hline PEC & 0.14 & 0.10 & 0.10 & 0.10 & 0.20 & 0.11 & 0.71 & & & & & & & & \\
\hline SANX & 0.10 & 0.08 & 0.04 & 0.15 & 0.08 & 0.09 & 0.18 & 0.67 & & & & & & & \\
\hline SPLAY & 0.06 & 0.12 & 0.12 & 0.10 & 0.16 & 0.11 & 0.28 & 0.07 & 0.64 & & & & & & \\
\hline ENJ & 0.10 & 0.15 & 0.14 & 0.12 & 0.22 & 0.10 & 0.25 & 0.21 & 0.18 & 0.80 & & & & & \\
\hline PEU & 0.21 & 0.12 & 0.08 & 0.16 & 0.21 & 0.10 & 0.35 & 0.14 & 0.24 & 0.26 & 0.63 & & & & \\
\hline $\mathrm{PU}$ & 0.11 & 0.07 & 0.16 & 0.16 & 0.21 & 0.07 & 0.14 & 0.21 & 0.17 & 0.22 & 0.26 & 0.72 & & & \\
\hline BI & 0.17 & 0.11 & 0.20 & 0.06 & 0.18 & 0.06 & 0.16 & 0.13 & 0.08 & 0.10 & 0.05 & 0.19 & 0.74 & & \\
\hline USE & 0.13 & 0.09 & 0.32 & 0.26 & 0.32 & 0.04 & 0.22 & 0.10 & 0.17 & 0.30 & 0.17 & 0.24 & 0.29 & 0.69 & \\
\hline SWT & 0.02 & 0.12 & 0.24 & 0.19 & 0.16 & 0.02 & 0.11 & 0.09 & 0.08 & 0.15 & 0.08 & 0.12 & 0.18 & 0.46 & 0.73 \\
\hline
\end{tabular}


Table 4. Study 2. SEM results

\begin{tabular}{|c|c|c|c|c|}
\hline Exogenous Variable & Endogenous Variable & $\begin{array}{c}\text { Std. } \\
\text { Estimate }\end{array}$ & S.E. & $\mathbf{P}$ \\
\hline Subjective Norm (SN) & Image $(\mathrm{IMG})\left(\mathrm{R}^{2}=0.25\right)$ & 0.50 & 0.061 & $<0.001$ \\
\hline Subjective Norm (SN) & \multirow{7}{*}{$\begin{array}{l}\text { Perceived Usefulness (PU) } \\
\left(\mathrm{R}^{2}=0.28\right)\end{array}$} & 0.14 & 0.053 & .017 \\
\hline Image (IMG) & & 0.09 & 0.053 & .099 \\
\hline Task Relevance (REL) & & 0.10 & 0.062 & .089 \\
\hline Output Quality (OUT) & & 0.05 & 0.042 & .372 \\
\hline Result Demonstrability (RES) & & 0.17 & 0.081 & .008 \\
\hline Perceived Ease of Use (PEU) & & 0.22 & 0.051 & $<.001$ \\
\hline REL X OUT & & 0.54 & 0.012 & $<0.001$ \\
\hline $\begin{array}{l}\text { Smartphone Self Efficacy } \\
\text { (SSE) }\end{array}$ & \multirow{5}{*}{$\begin{array}{l}\text { Perceived Ease of Use (PEU) } \\
\left(\mathrm{R}^{2}=0.45\right)\end{array}$} & 0.19 & 0.057 & .024 \\
\hline $\begin{array}{l}\text { Perceptions of External Control } \\
\text { (PEC) }\end{array}$ & & 0.34 & 0.061 & $<0.001$ \\
\hline Smartphone Anxiety (SNX) & & -0.16 & 0.054 & .001 \\
\hline Smartphone Playfulness (SPL) & & 0.18 & 0.072 & $<0.001$ \\
\hline Perceived Enjoyment (ENJ) & & 0.16 & 0.055 & .003 \\
\hline Perceived Usefulness (PU) & \multirow{2}{*}{$\begin{array}{l}\text { Behavioral Intention (BI) } \\
\left(\mathrm{R}^{2}=0.27\right)\end{array}$} & 0.28 & 0.056 & $<0.001$ \\
\hline Perceived Ease of Use (PEU) & & 0.18 & 0.057 & .002 \\
\hline Behavioral Intention (BI) & Use Behavior $(\mathrm{USE})\left(\mathrm{R}^{2}=0.13\right)$ & 0.27 & 0.046 & $<0.001$ \\
\hline Use Behavior (USE) & Switching Intention $\left(\mathrm{R}^{2}=0.27\right)$ & 0.19 & 0.052 & .015 \\
\hline
\end{tabular}

Fit Statistics: $\chi^{2} / \mathrm{df}=4.4 ;$ GFI=0.95; $\mathrm{AGFI}=0.92 ; \mathrm{CFI}=0.93 ; \mathrm{NFI}=0.92 ; \mathrm{RMR}=0.04 ; \mathrm{RMSEA}=0.06$ 


\section{DISCUSSION}

The adoption rates of mobile apps are becoming increasingly critical in the business realm due to ease-of-use, quick access to specialized content and engaging functionality (Kimberley, 2014). In this regard, the present study contributes to both the theory and practice of mobile app use behavior. The present study tests a theoretical model that explains the adoption of mobile applications. The model comprised of fifteen factors with three of them (viz. behavioral intention, use behavior and switching intention) as the outcomes of mobile app adoption. This research complements existing adoption studies in the field of mobile marketing by examining a specific perspective of mobile marketing, namely mobile apps adoption.

The present study adds a relevant and a novel contribution to the field of technology acceptance by extending the TAM theory to smartphone apps. It is expected that a technology will be adopted more rapidly if it has technological compatibility and ease of adoption (Benedetto, Calantone, \& Zhang, 2003). The present study supports this fact through the findings that perceived usefulness and perceived ease of use leads to app adoption. It has been observed that information and entertainment usefulness of app affects smartphone users' attitudes toward mobile apps usage. Thereby, it extends and validates the TAM3 (Venkatesh and Bala 2008) in the context of smartphone apps. Image, task relevance and output quality were not found to have significant effects on Perceived Usefulness. Image may not necessarily have an effect on app usage since app usage is an individual choice and it may not matter what other think. Though task relevance and output quality did not have significant direct effects, the significant indirect effect implies that in case an app is required, it is used and at that time, the quality has an influence on adoption. All behavioral variables such as smartphone selfefficacy; perceived external control and smartphone anxiety were found to affect perceived ease of use. This supports the need to include consumer's cognitive and conative components in a technology acceptance model (Venkatesh \& Bala 2008).

\section{MANAGERIAL IMPLICATIONS}

For mobile app marketers, our findings imply that mobile app users require appropriate combination of information and entertainment i.e., both information and entertainment usefulness positively affect smartphone users' mobile app adoption. The study sheds light on the determinants of smartphones apps among the users by highlighting the role of the extended technology adoption model. The finding of perceived usefulness and perceived ease of use on smartphone app usage intention supports the applicability of TAM in mobile apps and suggests that perceived usefulness is more important than ease of use. The study design allowed the measurement of usage behavior ex-post and the findings imply that smartphone users may start using commercial mobile apps if they find it useful and easy to use. This may subsequently result in a switch from laptop and PC based commercial activities to smartphone apps. Thus, it becomes important for a manager to convey the usefulness and ease of use of apps that can subsequently influence adoption. However, the marketer should also be aware of the consumer psyche (such as level of smartphone anxiety) so that they can reduce/increase the effects of the same to increase adoption. Managers can take advantage from our results to design and market apps so as to attract user's attention and affection and formulate affective marketing strategies.

\section{LIMITATIONS}

There are certain limitations of our study that create scope for future research without undermining the value of the present study. The study was conducted in India and the findings are specific to the Indian market. Thus, future studies could investigate the same model with 
data from different markets. Such a comparative study would increase generalizability of the present study and bring out contrasting results (if they exist). Second, we had young and young adults as the respondents who are known to be technology ready. Thus, a future study could address whether the same results would hold good for aged audience or even those with low technology readiness. Third, we did not include the issue of privacy affecting use and switching behavior (as our focus was on TAM). However, privacy is gaining importance as an influencer of mobile commerce use and thus its inclusion as a moderator in the same model could provide interesting findings. In spite of the limitations, the novelty of the study lies in its application of a tested framework (TAM) in a new mobile phone usage phenomenon and the findings generated provide thoughts to ponder for academicians and marketers.

\section{REFERENCES}

Accenture. (2012). Always On, Always Connected - Finding Growth Opportunities in an Era of Hypermobile Consumers, Retrieved from

http://www.accenture.com/SiteCollectionDocuments/PDF/Accenture_EHT_Research_20

12_Consumer_Technology_Report.pdf (accessed on February 13, 2016).

Ali, A., Wong, E., Meeker, G. \& Gill, D. (2011). The Mobile Shopping Framework Study: The Role of Mobile Devices in the Shopping Process, Retrieved from http://advertising.yahoo.com/industryknowledge/mobile-shopping-insight.html (accessed on February 13, 2016).

Balasubramanian, S., Peterson, R.A. \& Jarvenpaa, S.L. (2002). Exploring the implications of mcommerce for markets and marketing. Journal of the Academy of Marketing Science, 30(4), 348361.

Bamberger, P.A. (2008). Beyond contextualization: Using context in theories to narrow the micromacro gap in management research. Academy of Management Journal, 51(5), 839-846.

Barnes, S.J. (2002). The mobile commerce value chain: Analysis and future developments. International Journal of Information Management, 2(2), 91-108.

Benedetto, C. A., Calantone, R. J. \& Zhang, C. (2003). International technology transfer model and exploratory study in the People's Republic of China. International Marketing Review, 20(4), 446462.

Bhattacharjee, S., Gopal, R. D., Marsden, J. R. \& Sankaranarayanan, R. (2011). Digital goods and markets: Emerging issues and challenges. ,ACM Transactions on Management Information Systems. $2(2)$, article 8.

Butcher, D. (2011). Half of us Consumers Shop with Mobile Devices: Study, Retrieved from http://www.mobilecommercedaily.com/2011/04/20/half-of-us-consumers-shop-withmobiledevices-study (accessed on February 13, 2016).

Chen, L.D. \& Nath, R. (2004). A framework for mobile business applications. International. Journal of Mobile Communication, 2 (4), 368-381.

Chiem, R., Arriola, J., Browers, D., Gross, J., Limman, E., Nguyen, P.V., Sembodo, D., Young, S. \& Seal, K.C. (2010). The critical success factors for marketing with downloadable applications: Lessons learned from selected European countries. International Journal of Mobile Marketing, 5 (2), 43-56.

Chin, W. W. (1998). The partial least squares approach for structural equation modeling. In N.J. Mahwah, \& G. A. Marcoulides, (Eds.), Modern Methods for Business Research, pp.295336).Lawrence Erlbaum Associates, New York, NY.

Churchill, G. A. Jr. (1979). A paradigm for developing better measures of marketing constructs. Journal of Marketing Research, 16(1), 64-73. 
Craig, C. \& Douglas, S. (2012). International advertising research: Conceptual and methodological issues. In S.Okazaki, (Ed.), Handbook of Research on International Advertising, (pp.201-231). Edward Elgar, Northampton.

Davis, F. D. (1993). User acceptance of information technology: System characteristics, user perception and behavioral impact. ,International Journal of Man-Machine Studies, 38, 475-487.

Davis, F.D., Bagozzi, R.P. \& Warshaw, P.R. (1989). User acceptance of computer technology: A comparison of two theoretical models. Management Science, 35(8), 982-1003.

Figge, S. (2004). Situation-dependent services: A challenge for mobile network operators. Journal Business Research, 57 (12),1416-1422.

Ford, J., West, D. \& Sargeant, A. (2015). Emic and etic cross-cultural scale development. In Dato, M. Conway (Ed.), The Sustainable Global Marketplace, (pp. 387).Springer, NYC.

Fornell, C. and Larcker, D. F. (1981). Evaluating structural equation models with unobservable variables and measurement error. Journal of Marketing Research, 18(1), 39-50.

Gupta, S. (March 2013). For mobile devices, think apps not ads. Harvard Business Review, 71-75.

Hackman, J.R., \& Oldham G.R. (1980). Work Redesign, Reading, MA, Addison-Wesley.

Hair, J.F., Anderson, R.E., Tatham, R.L. \& Black, W.C.(2008), Multivariate Data Analysis, Prentice Hall, Upper Saddle River, New Jersey.

Hampton, K. N., Goulet, L. S., Rainie, L. \& Purcell, K. (June 16, 2011), "Social networking sites and our lives",PEW Research Internet Project, Retrieved from

http://www.pewinternet.org/Reports/2011/Technology-and-socialnetworks (accessed January 24, 2016).

Hassan, M., Kouser, R., Abbas, S. S. \& Azeem, M. (2014). Consumer attitudes and intentions to adopt smartphone apps: Case of business students. Pakistan Journal of Commerce and Social Sciences, 8 (3), 763-779.

Hayes, A. F. (2015). An index and test of linear moderated mediation. Multivariate Behavioral Research, 50(1), 1-22.

Hayes, A. F. \& Agler, R. A.(2014). On the standard error of the difference between independent regression coefficients in moderation analysis. Multiple Linear Regression Viewpoints, 4(2), 16-27.

Heinonen, K., \& Strandvik, T. (2007). Consumer responsiveness to mobile marketing. International Journal of Mobile Communications, 5 (6), 603-617.

Hoehle, H. \& Venkatesh, V. (2015). Mobile application usability: Conceptualization and instrument development. MIS Quarterly, 39 (2), 435-472.

Hong, W., Chan, F.K.Y., Thong, J.Y.L., Chasalow, L.C. \& Dhillon, G. (2013). A framework and guidelines for context-specific theorizing in information systems research. Information Systems Research, 25 (1), 111-136.

Hutton, G., McCann, U. \& Rodnick, S. ( 2009). Smartphone opens up new opportunities for smart marketing. Admap, 44, (11), 22-24.

Johns, G. (2006). The essential impact of context on organizational behavior. Academy of Management Review, 31(2), 386-408.

Johns, G.(2001). In praise of context. Journal of Organizational Behavior, 22 (1), 31-42.

Johnson, R. (2010). Apps culture reinventing mobile internet. Electronic Engineering Times, 1588, 2430.

Kimberley, J. (December 1, 2014). To app, or not to app? That is the question. The Enterprise-Utah's Business Journal, 19. 
Kline, R.B. (2011). Convergence of structural equation modeling and multilevel modeling. In M. Williams, and W.P. Vogt (Eds.), Handbook of Methodological Innovation in Social Research Methods, 562-589.Sage, London.

Ko, E., Kim, E.Y. and Lee, E.K. (2009). Modeling consumer adoption of mobile shopping for fashion products in Korea. Psychology \& marketing, 26 (7), 669-687.

Lai, Jung-Yu., Debbarma, S. \& Ulhas, K.R. (2012). An empirical study of consumer switching behaviour towards mobile shopping. International Journal Mobile Communications, 10 (4), 386404.

Lee, A.S., \& Baskerville, R.L. (2003). Generalizing generalizability in information systems research. Information Systems Research, 14 (3), 221-243.

Lee, G., \& Raghu, T. S. (2014). Determinants of mobile apps' success: Evidence from the app store market. Journal of Management Information Systems, 31 (2), 133-170.

Lee, Y., Kozar, K. A. \& Larsen, K. R. (2003). The technology acceptance model: Past, present, and future. Communications of the Association for Information Systems, 12 (1), 752-780.

Lewis, B. R., Templeton, G. F. \& Byrd, T. A. (2005). A methodology for construct development in MIS research. European Journal of Information Systems, 14 (4), 388-400.

Liu, C. Z., Au,Y. A. \& Choi, H. S. (2014). Effects of freemium strategy in the mobile app market: An empirical study of google play. Journal of Management Information Systems, 31(3), 326-354.

López-Nicolás, C., Molina-Castillo, F. J. \& Bouwman, H. (2008). An assessment of advanced mobile services acceptance: Contributions from TAM and diffusion theory models. Information \& Management, 45,359-364.

Lu,J., Yao, J. E. \& Yu, C.S. (2005). Personal innovativeness, social influences and adoption of wireless internet services via mobile technology. The Journal of Strategic Information Systems, 14(3), 245268.

Middleton, C. (2010). Delivering services over next generation broadband networks: Exploring devices, applications and networks. Telecommunications Journal of Australia, 60(59), 1-59.

Miniard, P.W. \& Cohen, J. B. (1979). Isolating attitudinal and normative influences in behavioral intention models. Journal of Marketing Research, 16(1), 102-110.

Netemeyer, R. G., Bearden, W. O. \& Sharma, S. (2003). Scaling procedures: Issues and applications, Sage Publications, London.

Nysveen, H., Pedersen, P. \& Thorbjornsen, H. (2005). Explaining intention to use mobile chat services: Moderating effects of gender. Journal of Consumer Marketing, 22 (5),. 247-256.

Okazaki, S. \& Barwise, P. (2011). Has the time finally come for the medium of the future? Journal of Advertising Research, 51 (1), 59-71.

Rousseau, D.M., \& Fried. Y. (2001). Location, location, location: Contextualizing organizational research. Journal of Organisational Behaviour, 22 (1), 1-13.

Sarker, S., \& Wells, J. P. (2003). Understanding mobile handheld device use and adoption. Communications of the ACM, 46 (12), 35-40.

Shi, W. (2009). An empirical research on users' acceptance of smart phone online application software. International Conference on Electronic Commerce and Business Intelligence, 106-110.

Smith, H., Milberg, S. and Burke, S. (1996). Information privacy: Measuring individuals' concerns about organizational practices. MIS Quarterly, 20 (2), 167-196.

Taylor, D. G., Voelker, T. A. \& Pentina, I. (2011). Mobile application adoption by young adults: A social network perspective. International Journal of Mobile Marketing, 6 (2), 60-70. 
Venkatesh, V. \& Bala, H. (2008). Technology acceptance model 3 and a research agenda on interventions. Decision Sciences, 39 (2), 273-315.

Venkatesh, V., Bala, H. \& Sykes, T.A. (2010). Impacts of information and communication technology implementations on employees' jobs in service organizations in India: A multi-method longitudinal field study. Production and Operations Management, 19(5), 591-613.

Venkatesh, V., Morris, M. G., Davis, G. B. \& Davis, F. D. (2003). User acceptance of information technology: Toward a unified view. MIS Quarterly, 27 (3), 425-478.

Venkatesh, V., Thong, J. Y. L. \& Xu, X. (2016). Unified theory of acceptance and use of technology: A synthesis and the road ahead. Journal of the Association for Information Systems, 17 (5), 328-376.

Venkatesh, V., Fred D. Davis, \& Michael G. Morris. (2007). Dead or alive? The development, trajectory and future of technology adoption research. Journal of the Association for Information System, 8 (4), 267.

Venkatesh, V. \& Davis, F.D. (2000). A theoretical extension of the technology acceptance model: Four longitudinal field studies. Management Science, 46(2), 186-204.

Walsh, S. P., White, K.M., Cox, S. \& Young, R.M. (2011). Keeping in constant touch: The predictors of young Australians' mobile phone involvement. Computers in Human Behavior, 27 (1), 333-342.

Wang, H-Y., Liao, C. \& Yang, L-H. (2013). What affects mobile application use? The roles of consumption values. International Journal of Marketing Studies, 5 (2), 11-22.

Warshaw, P. R. (1980). A new model for predicting behavioral intentions: An alternative to Fishbein. Journal of Marketing Research, 17 (2), 153-172.

Whetten, D.A. (2009). An examination of the interface between context and theory applied to the study of Chinese organizations. Management and Organization Review, 5(1), 29-55.

Wu,L., Kang, M. \& Yang, S.B. (2015). What makes users buy paid smartphone applications? Examining app, personal, and social influences. Journal of Internet Banking and Commerce, 20 (1), $1-22$. 